\title{
Synaptic Contributions to Focal and Widespread Spatiotemporal Dynamics in the Isolated Rat Subiculum In Vitro
}

\author{
L. Menendez de la Prida ${ }^{1}$ and B. Gal ${ }^{1,2}$ \\ ${ }^{1}$ Departamento de Neurobiología-Investigación, Hospital Ramón y Cajal, Madrid 28034, Spain, and ²Departamento Ciencias Morfológicas y Fisiología, \\ Universidad Europea de Madrid, Madrid 28670, Spain
}

\begin{abstract}
The subiculum, which has a strategic position in controlling hippocampal activity, is receiving significant attention in epilepsy research. However, the functional organization of subicular circuits remains unknown. Here, we combined different recording and analytical methods to study focal and widespread population activity in the isolated subiculum in zero $\mathrm{Mg}^{2+}$ media. Patch and field recordings were combined to examine the contribution of different cell types to population activity. The properties of cells leading field activity were examined. Predictive factors for a cell to behave as leader included exhibiting the bursting phenotype, displaying a low firing threshold, and having more distal apical dendrites. A subset of bursting cells constituted the first glutamatergic type that led a recruitment process that subsequently activated additional excitatory as well as inhibitory cells. This defined a sequence of synaptic excitation and inhibition that was studied by measuring the associated conductance changes and the evolution of the composite reversal potential. It is shown that inhibition was time-locked to excitation, which shunted excitatory inputs and suppressed firing during focal activity. This was recorded extracellularly as a multi-unit ensemble of active cells, the spatial boundaries of which were controlled by inhibition in contrast to widespread epileptiform activity. Focal activity was not dependent on the preparation or the developmental state because it was also recorded under $5 \mathrm{~mm}\left[\mathrm{~K}^{+}\right]_{\mathrm{o}}$ and in adult tissue. Our data indicate that the subicular networks can be spontaneously organized as leader-follower local circuits in which excitation is mainly driven by a subset of bursting cells and inhibition controls spatiotemporal firing.
\end{abstract}

Key words: hippocampus; subiculum; epilepsy; conductance; shunting inhibition; slices

\section{Introduction}

Neuronal circuits produce different patterns of activity depending on input configuration and physiological conditions. Among these patterns, the one that results from the spontaneous correlated activity in the absence of external inputs is likely to reflect the intrinsic architecture of the underlying network. Examples include ensemble activity of cortical circuits (Mao et al., 2001; Cossart et al., 2003), low-frequency cortical oscillations (Steriade et al., 1993; Sanchez-Vives and McCormick, 2000), and persistent activity (Goldman-Rakic, 1995). In all these cases, there is an intimate relationship between the electrophysiological cellular properties, the connectivity patterns, and the correlated spatiotemporal activity they produce.

The subiculum, which has a strategic position in controlling

Received Jan. 28, 2004; revised May 3, 2004; accepted May 4, 2004.

This work was supported by grants from the Spanish Ministry of Science and Technology (Programa Ramón y Cajal and BFI2003-04305). B.G. is supported by Convenio UEM OTRI 200301CII from the Universidad Europea de Madrid. We thank Drs. L. Graham, A. Araque, S. Canals, J. Tabak, A. Compte, and 0. Herreras for helpful discussions and critical reading of this manuscript. We also thank Dr. R. Miles for discussion, Dr. I. Cohen for Labview routines for spike detection, and J. M. Ibarz for technical help.

Correspondence should be addressed to Dr. L. Menendez de la Prida, Departamento de NeurobiologíaInvestigación (planta-1D), Hospital Ramón y Cajal, Ctra Colmenar Km 9, Madrid 28034, Spain. E-mail: liset.m.prida@hrc.es.

DOI:10.1523/JNEUROSCI.0309-04.2004

Copyright $\odot 2004$ Society for Neuroscience $\quad$ 0270-6474/04/245525-12\$15.00/0 hippocampal activity, is currently receiving much experimental attention. This interest derives from an emerging awareness of its role in spatial encoding (Sharp and Green, 1994; Taube, 1995; Ekstrom et al., 2003) and human epilepsy (Cohen et al., 2002). The subiculum is a single-layered network exhibiting a large electrophysiological diversity of neuronal types, including bursting and non-bursting glutamatergic cells and fast-spiking (FS) interneurons (Greene and Totterdell, 1997; Menendez de la Prida et al., 2003). The differential role of these cell types in processing is poorly understood, although it has been shown that bursting cells participate in sustaining hippocampal-generated gamma rhythms (Stanford et al., 1998) and epileptiform activity (Harris and Stewart, 2001; Cohen et al., 2002). Similarly, little is known about the organization of glutamatergic subicular networks, although a laminar and columnar architecture has been suggested (Harris et al., 2001). Inhibitory circuits, which are functionally recruited in a feedforward manner (Colino and De Molina, 1986; Finch et al., 1988), exert a control of bursting cell firing (Menendez de la Prida, 2003). However, despite this knowledge, a large experimental gap exists between what we know about subicular architecture and its function. The importance of this problem is twofold, first because the internal operation of the subiculum would shape its response properties during spatial orientation tasks (Sharp, 1999; Taube and Basset, 2003), and second because 
by understanding how the subiculum generates activity, the role of each cell type will be uncovered (Harris and Stewart, 2001; Kawaguchi, 2001).

To better understand the functional organization of subicular circuits, we examined the patterning of activity induced by bathing subicular minislices in zero $\mathrm{Mg}^{2+}$ media. Using this approach (Walther et al., 1986; Traub et al., 1994; Behr and Heinemann, 1996; Harris and Stewart, 2001), we could identify the cellular and synaptic initiators of population activity. We combined electrophysiological recordings at several levels [field potential, multi-unit activity (MUA), and patch recordings] with computational analysis of fieldassociated synaptic conductances, to build a comprehensive view of the operation of subicular circuits. Our results explored several aspects of neuronal processing such as: (1) the leading role of a subset of cells; (2) the role of shunting inhibition; and (3) the spatiotemporal patterning of population activity and its excitatory-inhibitory control. Our data indicate that the subicular networks can be spontaneously organized as leader-follower circuits in which excitation is mainly driven by a subset of bursting cells and inhibition controls spatiotemporal firing.

\section{Materials and Methods}

Minislice preparation, stimulation, and recordings. Horizontal slices (hippocampus/entorhinal cortex, $350 \mu \mathrm{m}$ ) were prepared from juvenile (17-20 d old) and adult (2 months old) Wistar and Sprague Dawley rats, as described previously (Menendez de la Prida et al., 2003). No differences were found in data from both strains. Extracellular solution [artificial CSF (ACSF)] contained (in mM): $125 \mathrm{NaCl}, 3 \mathrm{KCl}, 1 \mathrm{MgCl}_{2}, 1.2 \mathrm{NaH}_{2} \mathrm{PO}_{4}, 2 \mathrm{CaCl}_{2}, 22$ $\mathrm{NaHCO}_{3}$, and 10 glucose, $\mathrm{pH} 7.3$ when bubbled with $95 \% \mathrm{O}_{2}-5 \% \mathrm{CO}_{2}$. Population activity was enhanced either by omitting $\mathrm{MgCl}_{2}$ from the ACSF or by increasing $\left[\mathrm{K}^{+}\right]_{\mathrm{o}}$ to $5 \mathrm{~mm}$. The subiculum was isolated from the hippocampus, and the entorhinal cortex using a dissection scissor. Subicular minislices of different sizes were obtained, and their width was measured using a calibrated eyepiece (Fig. $1 A$ ). Slices were maintained in ACSF at room temperature for $1 \mathrm{hr}$ before being transferred to a submerged-type chamber (flow rate, $\sim 1.5 \mathrm{ml} / \mathrm{min} ; 32-34^{\circ} \mathrm{C}$ ) attached to an upright microscope (Olympus, Tokyo, Japan).

Extracellular field potentials were recorded using patch-clamp pipettes (borosilicate glass capillaries; outer diameter, $1.2 \mathrm{~mm}$; inner diameter, $0.69 \mathrm{~mm}$; Harvard Apparatus) filled with ACSF (tip resistance, $\sim 7$ $\mathrm{M} \Omega$ ). Signals were amplified and bandpass filtered at $0.1 \mathrm{~Hz}$ to $5 \mathrm{kHz}$ or at 0.1-300 Hz. MUA was recorded using a coated tungsten wire of 100 $\mu \mathrm{m}$ diameter etched to a point of $10-15 \mu \mathrm{m}$ diameter. The tip was then re-coated using an insulating resin to obtain a final resistance of $0.7-0.8$ $\mathrm{M} \Omega$ (uninsulated tip length, $\sim 100-150 \mu \mathrm{m}$ ). MUA signals were amplified using two independent low-noise amplifiers (P15; Grass Instruments, Quincy, MA) and bandpass filtered at $100 \mathrm{~Hz}$ to $5 \mathrm{kHz}$. For paired MUA recordings, the electrodes were separated $>200 \mu \mathrm{m}$ to avoid oversampling the same cellular population (Cohen and Miles, 2000). At the end of the recording session, a mark was made in the tissue and the interelectrode distance was measured.

Somatic patch-clamp recordings were made under visual control (60× immersion lens) using an Axoclamp 2B amplifier (Axon Instruments, Foster City, CA). Patch recordings were performed using both the
B

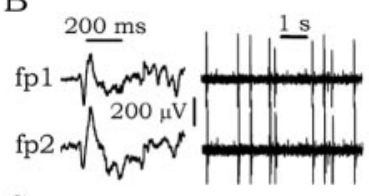

C

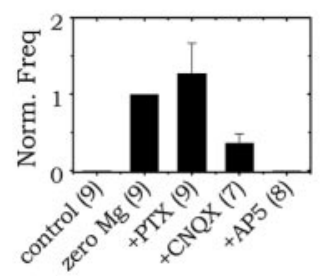

D

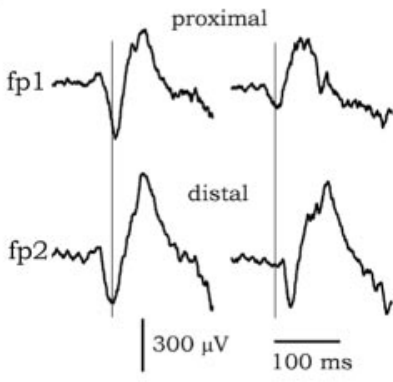

G
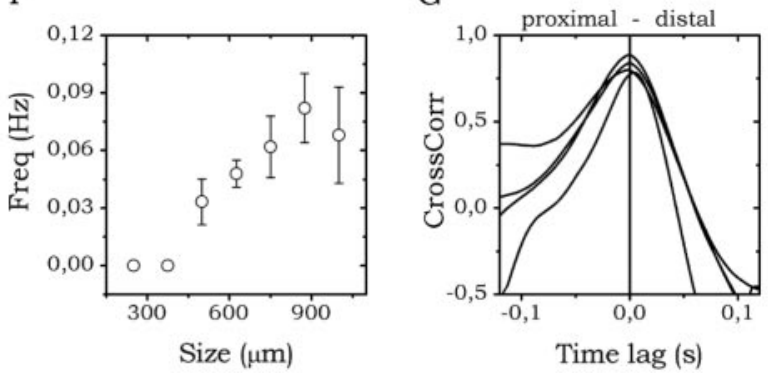

Figure 1. Experimental preparation. A, Isolated subicular minislices of different sizes (widths) were prepared from juvenile and

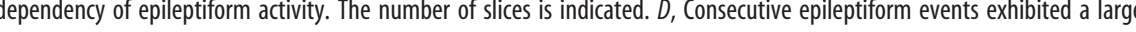
alysis of dual recordings ( 4 consecutive events) from the minislice shown in $E$, after re-sectioning ( $\sim 650 \mu \mathrm{m}$ wide). Same a cutting, $\sim 300 \mu \mathrm{m}$.

cell-attached configuration in the voltage-clamp mode and the wholecell configuration in the current- and voltage-clamp modes. Patch pipettes were filled with intracellular solution containing (in $\mathrm{mM}$ ) 113 K-gluconate, $6 \mathrm{KCl}, 1 \mathrm{MgCl}_{2}, 1 \mathrm{NaCl}, 1$ EGTA, 5 HEPES, $2 \mathrm{~K}_{2} \mathrm{ATP}, 0.3$ NaGTP, and Neurobiotin (0.1-0.5\%; Vector Laboratories, Burlingame, CA), pH 7.3 adjusted with $\mathrm{KOH}$ and osmolarity between 290 and 300 $\mathrm{mOsm}$. For some voltage-clamp experiments, the following solution was used (in mM): 115 Cs-gluconate, $4 \mathrm{MgCl}_{2}$, 1 EGTA, 5 HEPES, $2 \mathrm{Na}_{2} \mathrm{ATP}$, and $0.3 \mathrm{NaGTP}, \mathrm{pH} 7.3$ adjusted with $\mathrm{CsOH}$ and osmolarity between 290 and $300 \mathrm{mOsm}$. Patch pipettes had a resistance of $4-6 \mathrm{M} \Omega$. Capacitance compensation and bridge balance were performed before patching. The access resistance was calculated off-line from the cell response to subthreshold current pulses (double exponential fitting). The junction potential ( $\sim-7 \mathrm{mV}$ for K-based solution and $\sim-10 \mathrm{mV}$ for Cs-based solution) was corrected (Neher, 1994). All recordings were simultaneously digitized (Digidata 1200B; Axon Instruments) and stored on disk at a sampling frequency $>10 \mathrm{kHz}$. Monopolar stimulation (squarewave; 0.1 msec duration; $0.5-1 \mathrm{~mA}$ amplitude) was delivered via tungsten electrodes (tip diameter, $10-20 \mu \mathrm{m}$ ).

Morphological reconstruction and analysis. After each experiment, the minislice was fixed overnight in 4\% paraformaldehyde PBS (0.1 M; pH 7.4). Because of their small size, minislices were not dehydrated or resliced. After $\mathrm{H}_{2} \mathrm{O}_{2}(0.3 \%)$ and Triton X-100 (0.6\%) pretreatment, minislices were processed by incubation in a 1:100 dilution of an $\mathrm{ABC}$ kit (Vector Laboratories) for $3 \mathrm{hr}$. Visualization was performed using a solution of $0.03 \%$ of 3,3-diaminobenzidine and $0.005 \% \mathrm{H}_{2} \mathrm{O}_{2}$. The reaction was followed under visual control and stopped after 5-10 min depending on labeling intensity. Minislices were washed in TBS ( $0.5 \mathrm{M})$ and mounted on gelatin-coated glass slides using glycerol (50\% in TBS) and Eukitt mounting medium (Fluka, Neu-Ulm, Germany). More than $60 \%$ of Neurobiotin-filled cells were successfully recovered. Cells were drawn 
using $40 \times$ and $60 \times$ (dendritic tree) and $100 \times$ (axon collaterals) objectives and a camera lucida attachment. The dendritic arborization was quantified using the Scholl concentric ring analysis (Scholl, 1953). For this purpose, soma-centered concentric rings of increasing diameters of $25 \mu \mathrm{m}$ were drawn on the Camera Lucida reconstruction, and the number of dendritic crossings was counted (basal, negative numbers; apical, positive numbers). Axonal boutons were identified using a $100 \times$ oil immersion objective. No difference was found in the density of axonal boutons among different glutamatergic cell types. However, we cannot totally exclude this possibility because of a possible underestimation attributable to minislice thickness.

Electrophysiological classification of cell types. Subicular cells were electrophysiologically classified as weak (IB-) and strong (IB+) bursting, regular-spiking (RS) and FS, from their responses to depolarizing current pulses of $500 \mathrm{msec}$ duration (Stewart and Wong, 1993; Staff et al., 2000; Menendez de la Prida et al., 2002, 2003). Intrinsic properties were determined in $\mathrm{Mg}^{2+}$-free solution. Bursting cells firing only one burst in response to several suprathreshold current pulses were classified as IBcells, whereas those firing more than one burst were classified as IB+. Previous studies have shown that bursting and RS neurons are projection glutamatergic cells, whereas the FS type corresponds to inhibitory interneurons (Harris et al., 2001; Menendez de la Prida, 2003; Menendez de la Prida et al., 2003).

MUA activity: spike detection and firing rate data. Multiple spikes recorded using tungsten electrodes were detected off-line (Cohen and Miles, 2000). A Gaussian convolution was used to derive firing rate data (SD for convolution, $20 \mathrm{msec}$ ). In MUA recordings, collision of spikes may occur. This situation is more frequent while recording population activity that results from coordinated firing of several cells. In preliminary simulations, we estimated that pairs of spikes separated by intervals of $0.6-0.8 \mathrm{msec}(1250-1666 \mathrm{~Hz})$ could be resolved successfully.

Estimation of input conductance and composite reversal potential. Input conductance increases $(\Delta G)$ during focal field activity were measured using routines written in Matlab (MathWorks, Natick, MA) following the method of Borg-Graham et al. (1998). Conductance changes during the buildup period before epileptiform events could not be efficiently measured and are not discussed. Spontaneous synaptic currents associated with focal field activity were recorded in voltage clamp at three different holding potentials between -55 and $-75 \mathrm{mV}$ (transmembrane potential changes during field activity, $<1 \mathrm{mV}$ ). The holding potential was corrected for the drop across access resistance, which was lower than $30 \mathrm{M} \Omega[18 \pm 7 \mathrm{M} \Omega(n=19)$ and $19 \pm 9 \mathrm{M} \Omega(n=6)$ for K-gluconate and Cs-gluconate electrodes, respectively]. For each holding potential, four to six field-triggered spontaneous increases of synaptic activity were recorded and averaged. $G(t)$ was then derived from the slope of the linear regression at the $I-V$ plot. The regression coefficient $(r)$ ranged from 0.98 to 0.99 (see examples in supplementary Fig. 1; available at www.jneurosci.org), which suggest good voltage-clamp conditions and that voltagegated channels were not typically activated during voltage-clamp experiments. The relative conductance increase $\Delta G(t)$ was given as [ $G(t)$ Grest]/Grest in percentage, where Grest is the resting conductance. Similarly, the composite reversal potential of the synaptic input $\operatorname{Vrev}(t)$ was calculated as the voltage of the intersection between the $I-V$ curve at time $t$ and at rest. $\operatorname{Vrev}(t)$ is also known as the null-current potential. Because the intersection method is noisy for similar slopes, we only considered those cases in which synaptic conductance was $>5 \%$ than resting conductance.

To dissect the contribution of glutamatergic and GABAergic synaptic currents to the composite $\operatorname{Vrev}(t)$, we estimated the reversal potential of evoked EPSCs and IPSCs. CNQX- and AP-5-sensitive glutamatergic currents reversed at $-6 \pm 4 \mathrm{mV}(n=4$; see supplementary Fig. 1$)$. The reversal potential of $\mathrm{GABA}_{\mathrm{A}}$-mediated currents was $-72 \pm 2 \mathrm{mV}(n=$ 4 ), which coincides with the theoretical value predicted for our pipette solution. Because a use-dependent shift of Vrev has been described for these currents (Thompson and Gähwiler, 1989; Staley and Proctor, 1999), we also estimated changes induced by repetitive activation of $\mathrm{GABA}_{\mathrm{A}}$ receptors. Repetitive stimulation of $25-100 \mathrm{~Hz}$ at $250-400 \mathrm{msec}$ shifted the $\mathrm{GABA}_{\mathrm{A}}$-mediated reversal potential to $-64 \pm 4 \mathrm{mV}(n=4$; $p<0.05$ ), as measured $40 \mathrm{msec}$ after the train outset (see supplementary
Fig. 1). As described previously (Thompson and Gähwiler, 1989; Staley and Proctor, 1999), this shift was associated with an increase of intracellular $\mathrm{Cl}^{-}$concentration, because it was induced at holding potentials more positive than the $\mathrm{Cl}^{-}$equilibrium potential (i.e., holding potential, $-50 \mathrm{mV})$ but not at negative holding potentials $(-80 \mathrm{mV})$. The reversal potential of $\mathrm{GABA}_{\mathrm{B}}$-mediated currents was $-88 \pm 2 \mathrm{mV}(n=5$; data not shown).

We failed to obtain confident estimates of $G \operatorname{exc}(t)$ and $\operatorname{Ginh}(t)$ using methods described previously (Borg-Graham, 2001). The reason for that derived from the need to place constraints to solve algebraic equations, which substantially distorted results. This is especially critical when more than two components (NMDA, non-NMDA, $\mathrm{GABA}_{\mathrm{A}}$, and $\mathrm{GABA}_{\mathrm{B}}$ ) are contributing together and in the case when $\mathrm{GABA}_{\mathrm{A}}$-mediated currents exhibit a use-dependent shift of $\mathrm{Vrev}$. Another potential limitation arises from possible differences in the spatial distribution of excitatory and inhibitory inputs. Therefore, we used the temporal evolution of the $\operatorname{Vrev}(t)$ to characterize the differential contribution of excitation and inhibition.

Data analysis. Field potential and MUA firing rate data were analyzed using routines written in Matlab. Normalized cross-correlation functions were computed using fast Fourier transform algorithms. Latencies between dual field recordings were calculated from the peak offset of cross-correlation. The irregular nature of population activity was quantified by calculating the coefficient of variation $(\mathrm{CV}=\mathrm{SD} /$ mean $)$ of a given measure.

The intrinsic firing pattern and membrane properties of cells were tested in the whole-cell current-clamp mode, as described previously (Menendez de la Prida, 2003). Input resistance was determined from cell responses to hyperpolarizing current pulses of $500 \mathrm{msec}$ duration. To determine the relative [relative to resting membrane potential (RMP)] and absolute firing threshold, depolarizing pulses of increasing amplitude (50 msec duration) were injected at RMP. Firing threshold was defined at the inflection point of the voltage trace.

To examine the temporal correlation between single-cell firing and population activity, field-triggered data segments were used. For this purpose, $8-13$ data segments were triggered by the first negative field deflection detected over noise level $(\sim 20 \mu \mathrm{V})$. The mean amplitude of triggered data segments from field recordings had a CV that lies within $5-15 \%$. The latency to the first spike recorded in the cell-attached mode was calculated, and histograms for each cell were obtained. To evaluate the role of distinct cell types, histograms from similar electrophysiological categories ( $\mathrm{IB}+, \mathrm{IB}-$, RS, and FS) were pooled. Histograms from individual cells showed variability because of their irregular firing pattern. It was therefore important to statistically average the contribution of each cell over several data segments. For this purpose, we introduced the driving index $(\sigma)$ as a measure of the probability of a given cell to start firing before the field:

$$
\sigma=\frac{\# 1^{\text {rst }} \text { spikes }_{t<0}}{\# 1^{\text {rst }} \text { spikes }_{\text {total }}}
$$

A driving index $\sigma=0$ identified those cells that fire after the field in all data segments (followers), whereas a driving index $\sigma=1$ identified those cells that only fire before the field (leaders). A driving index $\sigma=0.5$ means that it is not possible to statistically define a leader/follower firing pattern for that cell.

Results are given as means $\pm \mathrm{SD}$, with the number of minislices (or cells) indicated in every case. Results were compared using Student's $t$ test or the ANOVA test. Simple linear regression was performed with a confidence interval of $95 \%$.

Drugs. Picrotoxin (PTX), 2,3-dioxo-6-nitro-1,2,3,4-tetrahydrobenzo[f] quinoxaline-7-sulfonamide (NBQX), CNQX, AP-5, atropine, mecamylamine, and salts were purchased from Sigma (St. Louis, MO). Hydroxy-saclofen, $\alpha$-methyl-4-carboxyphenylglycine (MCPG), and $\alpha$-methyl-4-phosphonophenylglycine (MPPG) were obtained from Tocris Cookson. 


\section{Results}

Temporal dynamics of population activity in the isolated subiculum in vitro

Lowering extracellular $\mathrm{Mg}^{2+}$ induced spontaneous epileptiform activity in the isolated subiculum after $10-20 \mathrm{~min}$ ( $\sim 70 \%$ minislices) (Behr and Heinemann, 1996; Harris and Stewart, 2001). Recordings were performed once activity stabilized, between $30 \mathrm{~min}$ and $2 \mathrm{hr}$ after washout of $\mathrm{Mg}^{2+}$. Epileptiform activity was recorded at both the proximal (near CA1) and distal (near pre-subiculum) borders (Fig. $1 A, B$ ), indicating the widespread activation of all subicular cells. Local field activity was also detected (see be-

low). The intervals between epileptiform events were widely irregular (mean frequency, $0.26 \pm 0.19 \mathrm{~Hz}$; CV, $48 \pm 15 \% ; n=$ 13) (Fig. $1 B$, right traces). The $\mathrm{GABA}_{\mathrm{A}}$ receptor antagonist PTX $(100 \mu \mathrm{M})$ increased $1.3 \pm 0.4$ times the frequency of epileptiform activity $(0.21 \pm 0.07 \mathrm{~Hz} ; \mathrm{CV}, 46 \pm 23 \% ; n=9)$, which was blocked by AP-5 (100 $\mu \mathrm{M} ; n=8)$ and strongly reduced by NBQX $(n=2)$ or CNQX $(n=6)$ at $10 \mu \mathrm{M}$ (Fig. $1 C)$.

To investigate whether there is a clear leading region of epileptiform activity, we performed cross-correlation analysis of dual field recordings. We looked for the appropriate slice width (Fig. 1A) for which epileptiform activity was spontaneously generated with minimal temporal variations. Minislices 900-1300 $\mu \mathrm{m}$ wide showed large variability of latencies between dual field recordings separated $\sim 300 \mu \mathrm{m}(\mathrm{CV}, 76 \pm 33 \%)$ (Fig. $1 E)$. Epileptiform activity was not recorded in minislices $<500 \mu \mathrm{m}$ wide $(n=9)$ (Fig. 1F). Minislices $500-750 \mu \mathrm{m}$ wide $(n=15)$ were less excitable than minislices $>750 \mu \mathrm{m}$ wide $(n=15)$ (Fig. $1 F)$. Interestingly, latency variations were significantly reduced in smaller minislices, and mean latency significantly decreased to $-1.4 \pm 1.9 \mathrm{msec}$ (versus $-14.6 \pm 4.4$ before cutting; same interelectrode distance before and after cutting; $n=4 ; p<0.005$ ) (Fig. $1 G$ ).

Therefore, similar to the hippocampus (Miles et al., 1984), the site of origin of population activity in the subiculum is spatially constrained in minislices 500-750 $\mu \mathrm{m}$ wide (latency, $\sim 0 \mathrm{msec}$ ). This also guaranteed that latencies are conserved among different episodes of field activity. We used this approach to better understand how different cell types interact to generate field activity in the isolated subiculum.

\section{Focal and widespread field activity in the isolated subiculum}

To examine the relationship between single-cell firing and population activity, cell-attached recordings were initially obtained. Whole-cell configuration in current and voltage clamp was then established to characterize membrane properties and synaptic activity. We took special care to avoid artificial delays between patch and field recordings by minimizing their relative distance $(\sim 20-50 \mu \mathrm{m})$. The maximal error introduced was estimated from the delay between the cell and field spike evoked by local stimulation $(0.1 \pm 0.8 \mathrm{msec} ; n=4$ cells $)$. A total of 54 cells were recorded: 17 were classified as $\mathrm{IB}+, 17$ were $\mathrm{IB}-, 12$ were $\mathrm{RS}$, and 8 were of the FS type (Table 1; see Materials and Methods).

We classified field activity as desynchronized, widespread, and focal (Fig. 2). During periods of desynchronized activity, irregular cell firing was present mostly in FS and bursting cells (Fig. 2A; Table 1). The nature of this firing could be intrinsic or synaptic, because spontaneous EPSCs were evident in voltage-clamp con- figuration (Fig. $2 A$, vc trace) and EPSP-driven firing was present in current-clamp configuration (Fig. $2 A$, cc trace). Periods of desynchronized field activity were characterized by a flat crosscorrelation of dual field recordings separated $450 \pm 69 \mu \mathrm{m}(n=$ 7) (Fig. 2D).

During widespread population activity (Fig. $2 E$ ), cell firing was recorded simultaneously with epileptiform field events (Fig. $2 B$ ). Interestingly, some cells (mostly bursting cells) increased their firing 50-100 msec before the onset of field events. Recordings under current and voltage clamp showed that this was associated with an increase of synaptic activity (Fig. $2 \mathrm{~B}, \mathrm{cc}$ and $\mathrm{vc}$ traces). This buildup period has been described in other in vitro models of epilepsy (Chamberlin et al., 1990; Traub and Dingledine, 1990) and in immature population activity (Menendez de la Prida and Sanchez-Andres, 1999; Wenner and O'Donovan, 2001).

The combination of cell-attached and field recordings facilitated the identification of focal activity (Fig. 2C), which was characterized by low-amplitude changes in the field that could be associated with cell firing. The mean, but not the variance, of the distribution of field event amplitude was different in focal (74 \pm $28 \mu \mathrm{V})$ versus widespread episodes $(131 \pm 54 \mu \mathrm{V}$; data from 21 events from $n=7$ minislices; $p=0.05)$. Once in whole-cell configuration, barrages of synaptic activity were evident in current- and voltage-clamp simultaneous to focal field activity (Fig. 2C, cc and vc traces). Not all the cells recorded exhibited firing in correlation with focal activity. Those that did included 5 of $17 \mathrm{IB}+$ cells, 5 of $17 \mathrm{IB}-$ cells, 5 of 12 RS cells, and 6 of 8 FS interneurons. This suggests that only a fraction of cells contribute to the averaged field changes (see below). Focal activity occurs erratically, with no clear periodicity (mean frequency, $0.36 \pm$ $0.16 \mathrm{~Hz} ; \mathrm{CV}, 58 \pm 18 \% ; n=22$ minislices). The absence of peaks in the auto-correlation (data not shown) and cross-correlation functions (Fig. $2 F$ ) from dual field recordings confirmed its local non-oscillatory nature and suggested that focal activity was not related with waves of activity across the tissue.

Role of bursting and FS cells in the generation of focal activity We first examined the contribution of each cell type to focal activity using field-triggered data segments from cell-attached recordings (see Materials and Methods). Both $\mathrm{IB}+(n=5)$ and IB $-(n=5)$ cells that participated in focal activity typically began to fire before the field activity $[-13 \pm 35 \mathrm{msec}(n=41$ episodes from five IB + cells) and $-12 \pm 41 \mathrm{msec}(n=40$ episodes from five IB + cells)] (Fig. $3 A, B)$. In contrast, RS cells were activated after the field activity $(12 \pm 25 \mathrm{msec} ; n=40$ episodes from five 
A

desynch

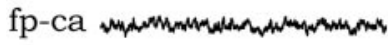

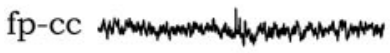

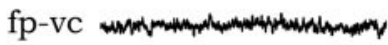

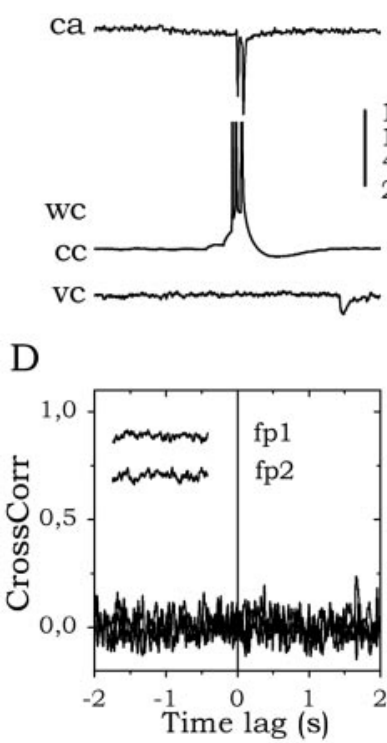

B

widespread

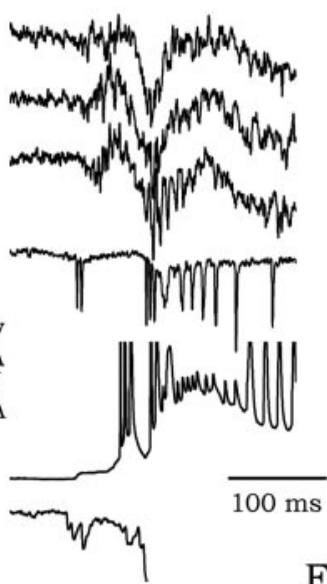

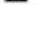

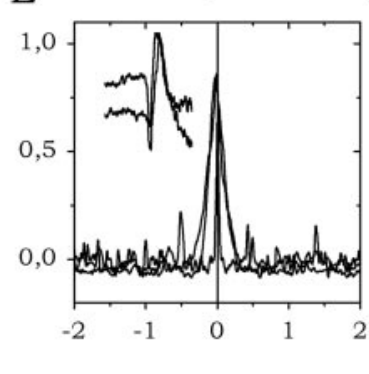

C
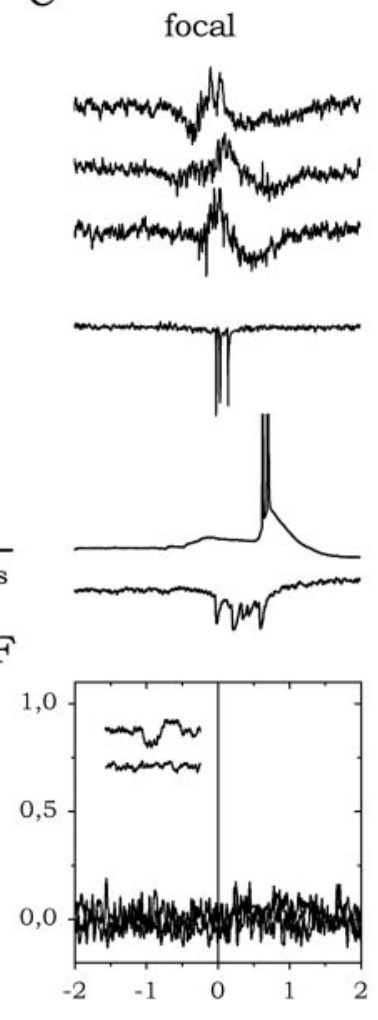

Figure 2. Simultaneous field ( $\mathrm{fp}$ ) and patch recordings. Cell responses were examined using cell-attached (ca) and whole-cell (wc) configurations in the current-clamp (cc) and voltage-clamp (vc) modes. Field recordings corresponding to ca, cc, and vc traces are depicted. $A$, Simultaneous field and patch recordings during desynchronized field activity. This cell was classified as weak bursting ( $\mathrm{IB}-)$. B, Simultaneous field and patch recordings during widespread field activity. C, Simultaneous field and patch recordings during focal field activity. $D$, Cross-correlation analysis of simultaneous field recordings. Results are shown from three consecutive episodes of desynchronized field activity. E, Widespread activity. F, Focal activity. Insets show examples of dual field recordings ( $\mathrm{fp} 1$ and $\mathrm{fp} 2)$.

cells) (Fig. $3 A, B$ ), and a same cell could remain silent during some episodes (Fig. $3 A$, RS cell). In addition, bursting cells typically fired bursts, whereas RS cells fired single spikes (Fig. $3 A$ ). We also examined the behavior of FS interneurons. Similar to RS cells, FS interneurons began to fire 10-12 msec after focal field activity (11 $\pm 15 \mathrm{msec} ; n=64$ episodes from six cells) (Fig. $3 B$ ), but in contrast to the glutamatergic cell type, this was followed by high-frequency firing (Fig. $3 A, C$ ).

These data suggest that both IB + and IB- cells constituted the first glutamatergic type that initiates a focal recruitment process that subsequently activates RS and FS cells. FS interneurons would in turn suppress activity. To test this idea, we looked at the field-triggered synaptic changes in 20 cells $(5 \mathrm{IB}+, 5 \mathrm{IB}-, 5 \mathrm{RS}$, and $5 \mathrm{FS}$ ) and examined the temporal correlation between excitation and inhibition using the composite reversal potential (see Materials and Methods).

\section{Glutamatergic- and GABAergic-mediated synaptic activity during focal activity}

In most cells (12 of 19: $4 \mathrm{IB}+, 4 \mathrm{IB}-$, and $4 \mathrm{RS}$ ), excitatory synaptic currents were recorded at the onset of focal field activity (Fig. 3D,E). The composite $\operatorname{Vrev}(t)$ typically showed a depolarized shift during the first $50-70 \mathrm{msec}$ (peak value, $-31 \pm 11 \mathrm{mV}$; $n=12)$ (Fig. $3 G$, black trace), which suggests a dominance of glutamatergic excitatory currents. No differences were found between IB+ $(-28 \pm 17 \mathrm{mV} ; n=4), \mathrm{IB}-(-34 \pm 17 \mathrm{mV} ; n=4)$, and RS cells $(-27 \pm 5 \mathrm{mV} ; n=4)$. All FS cells examined also exhibited a peak value of $\operatorname{Vrev}(t)$ that was even more depolarized than in glutamatergic cells $(-7 \pm 5 \mathrm{mV}$; $n=5 ; p<0.005)$. Because both $\mathrm{IB}+$ and IB- cells were the major glutamatergic type activated before the onset of focal activity, this analysis supports their role in the recruitment process. In addition, it also supports that FS cells experience strong glutamatergic activation at the onset of field activity.

Some bursting (IB+, one of five; IB-, one of five) and RS cells (one of five) exhibited inhibitory synaptic currents at the onset of focal activity (Fig. 3F, current trace at $-58 \mathrm{mV}$ holding potential). In these cases, the composite $\operatorname{Vrev}(t)$ showed a drop toward negative potentials $\sim-75$ $\mathrm{mV}$, near the reversal potential of control $\mathrm{GABA}_{\mathrm{A}}$-mediated chloride currents (Fig. $3 F, G$, gray trace). Because most FS interneurons began to fire $12 \mathrm{msec}$ after the field (Fig. 3B), this probably reflects the effect of a fast inhibitory surround. A second barrage of excitatory synaptic activity was evident in these cells (Fig. $3 F$ ), as showed by the shift of $\operatorname{Vrev}(t)$ toward positive values (Fig. $3 G$, gray trace). This glutamatergic component could be related to the secondary recruitment of RS cells or with sustained activity of bursting cells (Fig. 3B).

In some neurons ( 5 of 20), long-lasting synaptic currents were recorded (Fig. 3D, gray shading). Their GABAergic nature was suggested by comparison with the temporal course of interneuron firing during field-triggered data (Fig. $3 A, C, D$ ) and by its reversal potential (Fig. $3 E$ ). The composite $\operatorname{Vrev}(t)$ showed a negative shift 150-200 msec after the onset of focal activity ( $-88 \pm 6 \mathrm{mV} ; n=5)$ (Fig. 3G, black trace). This is consistent with a late prevalence of $\mathrm{GABA}_{\mathrm{B}}$-mediated currents.

\section{Role of different cell types in the initiation of widespread epileptiform activity}

We also examined the contribution of each cell type to the onset of widespread epileptiform activity using field-triggered averages. We found that both IB + and IB - cells began to fire $50-100$ msec before the onset of widespread epileptiform activity (Fig. $4 A, B)$. In contrast, RS cells tended to fire after the onset of epileptiform activity (Fig. 4C). Most FS interneurons fired at the onset, although some firing increases were detected before (Fig. 4D).

A second observation was evident when comparing histograms of single-cell firing during widespread and focal activity. During focal activity, bursting cells had a peak of firing before the field activity and subsequently decreased firing as the RS and FS firing increased (Fig. 3B). In contrast, generation of widespread activity was associated with a preceding monotonic increase of bursting cell firing that reached a peak at the onset of the widespread activity (Fig. 4A,B). Both RS and FS cells had similar spike time histograms in focal versus widespread field activity. This 
A
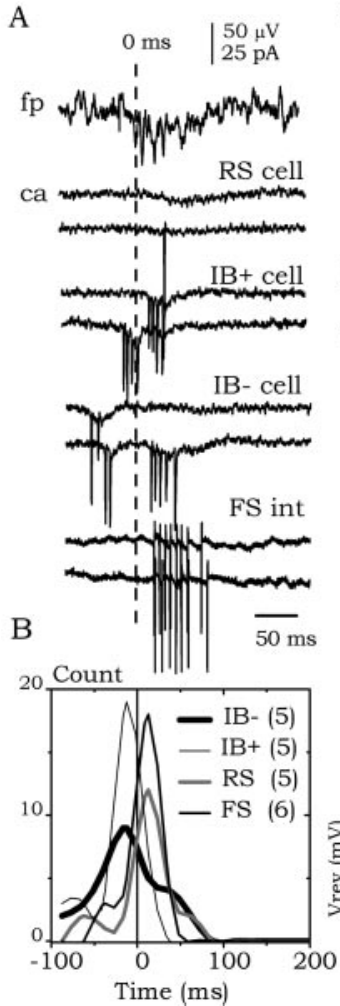

$\mathrm{C}$
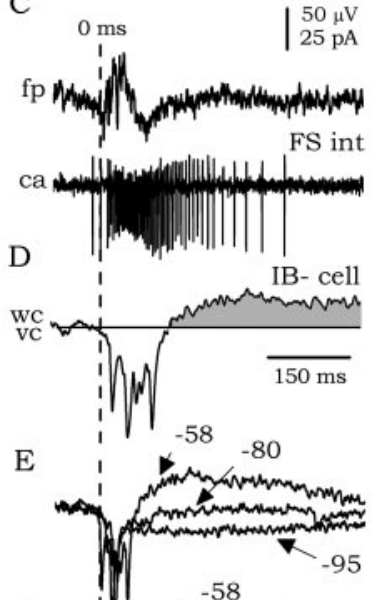

$\mathrm{F}$
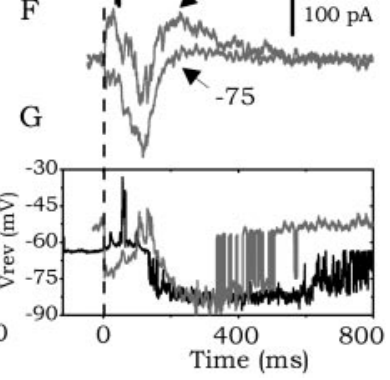

Figure 3. Cellular and synaptic behavior underlying focal activity. $A$, Cell responses in cellattached (ca) configuration during focal activity were examined using field-triggered data segments (fp trace). Two consecutive episodes are shown for each cell ( $\mathrm{RS}, \mathrm{IB}+$, IB - , and FS cells). $B$, Histograms of cell firing from each cell type. C, Representative response from another FS interneuron (ca trace) triggered by the onset of focal field activity (fp trace). Note the different time scale compared with A. D, Field-triggered synaptic currents from an IB - cell. E, Fieldtriggered synaptic currents from the cell shown in $D$ at three different holding potentials $(-58$, -80 , and $-95 \mathrm{mV}$ ). $F$, Field-triggered synaptic currents from a different IB - cell at two holding potentials. G, Field-triggered composite reversal potential from cells shown in $E$ (black trace) and $F$ (gray trace). $E-G$ share the same time scale (shown in $G$ ).

suggests that bursting cells are critical in initiating widespread forms of population activity and that FS cell firing, which is timelocked to leading cell firing, plays a role in controlling runaway excitation.

However, the temporal correlation between cell firing and the field activity varied among different episodes of focal and widespread activity. For a given cell, firing could occur before or after the onset of field activity (Fig. $5 A$; see also Fig. $3 A$, IB+ cell), suggesting that they variably participated in correlated firing. We defined the driving index $(\sigma)$ as a statistical measure of the probability of a given cell to fire before the field activity by examining its behavior in 10-13 consecutive episodes of population activity (see Materials and Methods).

Both IB + and IB - bursting cells exhibited a higher driving index than RS cells (Table 1) $(p<0.05)$. Nevertheless, the mean $\sigma$ from bursting cells was $<0.5$, a statistical limit separating the leader and follower firing pattern (see Materials and Methods). This suggests that in statistical terms, bursting cells did not define a glutamatergic leader population (although 15 of 34 cells had $\sigma>0.5$ ). The RS group, in contrast, behaved as a follower (mean $\sigma=0.08 \pm 0.13 ; n=12$ ). All but one FS interneuron (seven of eight) had a driving index $<0.5$, indicating that they were typically activated afterward.

\section{The driving capacity of a cell is mainly determined by} electrophysiological and morphological factors

Intrinsic electrophysiological properties such as resting membrane potential, input resistance, membrane time constant, and firing threshold could affect the firing capacity of a cell on synaptic activation. We examined these electrophysiological parameters among different cell types and found the firing threshold to be the most critical factor (Fig. 5B) (correlation coefficient $r=$ $-0.58 ; p<0.05$ ). Interestingly, bursting cells had a lower firing threshold (relative) than RS cells (Table 1). A higher input resistance in RS cells would favor their synaptic recruitment, but these cells exhibited the highest firing threshold. FS cells had high input resistance and a lower firing threshold than RS cells.

To address the possibility that those cells displaying $\sigma>0.5$ received stronger synaptic activation, we examined the temporal evolution of synaptic conductance changes during field-triggered focal activity in a subset of cells ( $n=17$; see Materials and Methods) (Fig. 5C,D). The composite $\operatorname{Vrev}(t)$ initially evolved toward depolarized values and then hyperpolarized as the conductance reached a peak (Fig. 5D). This evolution is better depicted in Fig. $5 E$, in which $\Delta G(t)$ is plotted as a function of the $\operatorname{Vrev}(t)$ during the first milliseconds before reaching the conductance peak (arrows). From these plots, clearly the conductance increases associated with the Vrev peak (open circles; $-27 \pm 15 \mathrm{mV}$ ) were lower than the conductance peaks (gray circles; $p<0.055$ ), which are associated with a Vrev of $-56 \pm 8 \mathrm{mV}$. This suggests that during conductance peaks concurrent contribution of inhibition and excitation existed. Values of conductance peaks and conductance increases at Vrev peak were similar in the three glutamatergic cell types (Table 2). FS interneurons were subject to larger increases than RS and bursting cells (Table 2) $(p<0.005)$. We did not find a good correlation between conductance increases in glutamatergic cells and their driving index $(r=0.13 ; p>0.05)$. Additional experiments were performed using a cesium-based patch solution $(n=6)$. The driving index of these cells (ranging from 0 to 1) was established in the cell-attached configuration. No correlation between conductance changes and the driving index was documented $(r=0.12 ; p>0.05)$.

The subtle depolarized Vrev at peak conductance suggests a shunting GABAergic effect over excitatory inputs (Fig. 5D). A use-dependent shift of the $\mathrm{GABA}_{\mathrm{A}}$ reversal potential could also contribute (see Materials and Methods). Therefore, it could be possible that proximal GABAergic inputs mask distal excitatory ones (Koch et al., 1990). Space-clamp errors of distal inputs could also contaminate these results (Spruston et al., 1993). We therefore explored whether differences in apical/basal dendritic arborization were correlated with the driving index in a group of morphologically reconstructed cells $(n=15)$.

As reported previously, no difference in dendritic morphology was found between bursting and RS subicular cells (Staff et al., 2000; Harris et al., 2001). However, when cells were grouped by the driving index ( $\sigma=0, n=5$ cells; $\sigma>0.5, n=4$ cells), the difference in the number of distal dendritic crossings was evident at $250-450 \mu \mathrm{m}$ from the soma (Fig. $6 \mathrm{~A}$, arrow). The mean number of distal crossings from all cells showed a significant correlation with the driving index (Fig. $6 C)(r=0.76 ; p<0.05)$. No difference in the spatial distribution of cells was present (Fig. $6 D$ ). Therefore, the difference in distal crossings suggests that driving cells may receive more inputs at secondary distal dendrites than follower cells. The good linear regression of $I-V$ data (regression coefficient, 0.98-0.99) suggests good voltage-clamp condition and that voltage-gated channels were not activated. However, although reliable estimates of the Vrev of synaptic cur- 
A

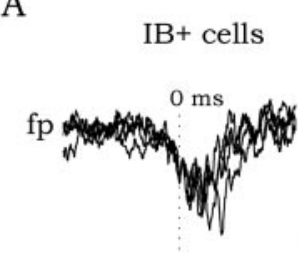

ca
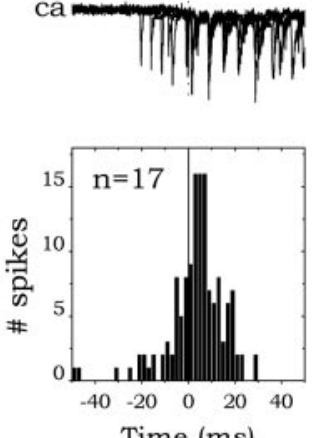

Time $(\mathrm{ms})$
B
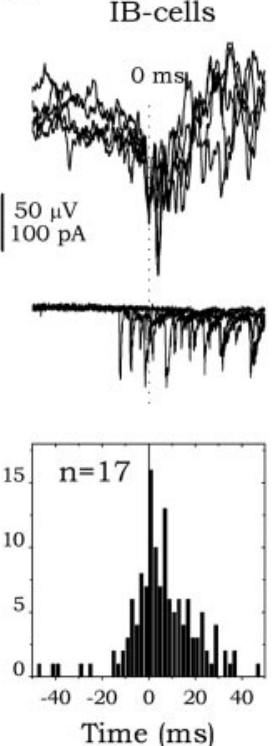

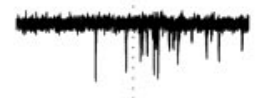

$\mathrm{C}$
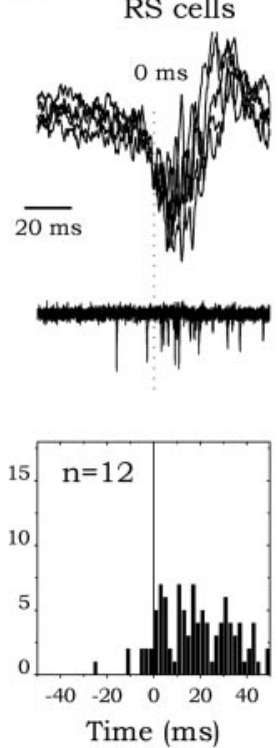

Figure 4. Cell behavior underlying widespread activity. Field-triggered ( $f p)$ cell responses ( 5 consecutive events are depicted) in a cell-attached configuration (ca) from representative $\mathrm{IB}+(A), \mathrm{IB}-(B), \mathrm{RS}(C)$, and FS $(D)$ cells. Firing histograms from all cells in each group are shown at the bottom.

A

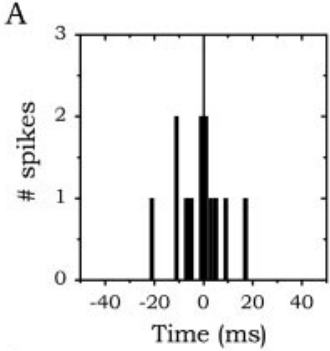

C

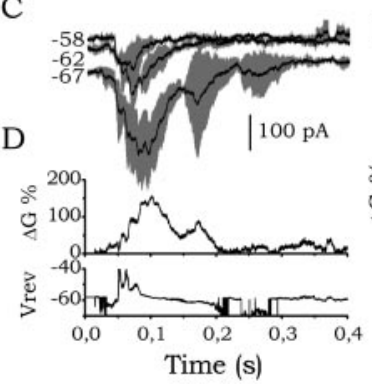

B

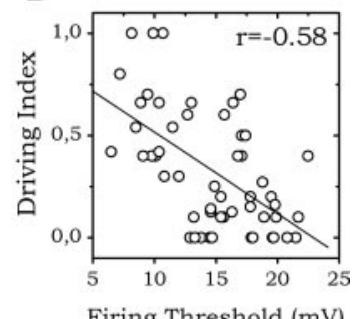

E

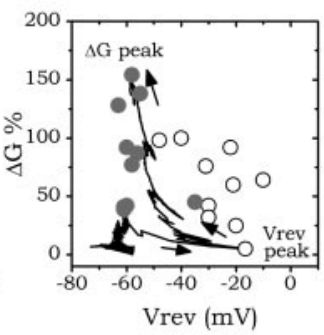

Figure 5. Electrophysiological properties and the driving index. A, Example of firing histograms from one cell (IB + cell) in cell-attached recordings during field-triggered activity (data from 13 consecutive episodes). The driving index measures the probability of a given cell to fire before the field (see Materials and Methods). B, Statistically significant correlation $(p<0.05$; $r=-0.58$ ) between the firing threshold and the driving index ( $n=46$ glutamatergic cells). $C$, Field-triggered averages (black traces) of synaptic currents during focal activity at three holding potentials. SDs are shown in gray. D, Conductance changes (up) and composite reversal potential (bottom) computed from data in C. E, Vrev- $\Delta G$ phase plots (see Materials and Methods and Borg-Graham et al. 1998). $\Delta G(t)$ is plotted as a function of the $\operatorname{Vrev}(t)$ during the first milliseconds before reaching the conductance peak. Arrows mark this temporal evolution. Gray circles denote the $V r e v, \Delta G$ values at conductance peak. Open circles denote the $V r e v, \Delta G$ values at the Vrev peak. Note the shunting effect of peak conductance increases (gray dots).

rents located $250-400 \mu \mathrm{m}$ from the soma can be obtained (2-3 $\mathrm{mV}$ error), conductance values are significantly reduced by $>20 \%$ because of space-clamp errors (Spruston et al., 1993). Therefore, the lack of correlation with somatic conductance changes could be related to significant electrotonic filtering.

D
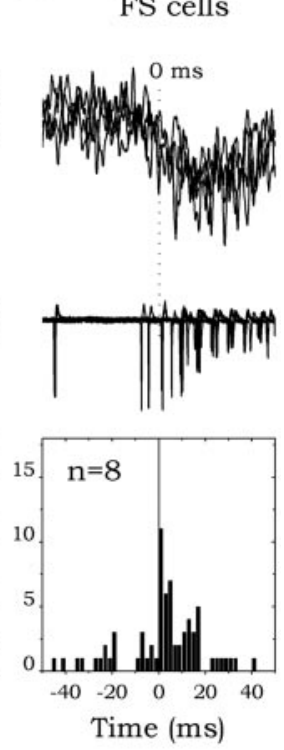

MUA recordings during

desynchronized, focal, and widespread population activity

Together, these results suggest that although some bursting cells play a leader role, network activation is a probabilistic process that needs the local recruitment of several cell types. Periods of focal activity seem to reflect the functional architecture of the underlying network with bursting, RS and FS cells differentially sculpting the spatiotemporal patterning. To gain in spatiotemporal resolution of the network activity, we combined field and multi-unit recordings. We used pharmacological tools to dissect the underlying circuit mechanism.

Data collected using MUA recordings were consistent with the picture that emerged from cell-attached recordings. Desynchronized, widespread, and focal field activities were correlated with three different MUA patterns (Fig. 7). During desynchronized field states, multi-unit firing was recorded (Fig. 7A). Both single spikes and bursts (Fig. 7A, inset a) of different amplitudes were erratically detected, suggesting the spontaneous activation of different cells. During widespread epileptiform activity, high-frequency firing was recorded in correlation with large field epileptiform events (Fig. 7B). Interestingly, firing increases were detected 50-100 msec before the onset of field events, which matched the buildup period. Cell ensemble activity was evident in MUA recordings during focal field activity (Fig. 7C). The amplitude, number, and sequence of spikes recorded within these ensembles varied substantially, confirming that many cells were variable recruited during consecutive episodes. This was also manifested in the variability of ensemble duration (124 $\pm 34 \mathrm{msec}$; CV, $57 \pm 16 \% ; n=11$ minislices). Ensemble activity during focal activity was similar to MUA activity detected before the onset of widespread field activity (Fig. 7, compare $B, C$ ).

\section{Pharmacological dissection of synaptic factors contributing to focal field activity}

We took advantage of the higher spatiotemporal resolution of MUA recordings to pharmacologically dissect the synaptic contributions to focal field activity. For this purpose, we initially addressed the question of what are the sources of cell firing during desynchronized activity by examining changes of firing rate under different receptor antagonists (Fig. 8A). We first derived confidence intervals of a firing rate from MUA recordings of $1 \mathrm{hr}$ duration. Changes of $14 \%$ were not statistically significant $(n=5$ minislices).

Lowering extracellular $\mathrm{Mg}^{2+}$ induced a subtle increase of firing during desynchronized field activity $(n=7)$ (Fig. 8 B). Most of this firing had a glutamatergic origin because it was reduced to $29 \pm 18 \%$ of control by suppressing glutamatergic transmission with CNQX (or NBQX) and AP-5 $(n=6)$ (Fig. $8 B)$. This was confirmed by adding a mixture of antagonists containing MCPG and MPPG $(1 \mathrm{mM})$, atropine $(1 \mu \mathrm{M})$, mecamylamine $(20 \mu \mathrm{M})$, and saclofen $(200 \mu \mathrm{M} ; n=4)$ (Fig. $8 B)$.

We next wondered about the synaptic components of focal field activity. Data from patch recordings suggested an initial 
glutamatergic activation, followed by a composite GABAergic component. Using pharmacological tools, we confirmed that NMDA, but not non-NMDA, transmission was critical in the generation of focal activity that was blocked by AP-5 (Fig. $9 A, C)$.

Consistent with a role of inhibition in firing cessation, both saclofen and PTX induced an increase of ensemble duration $(n=5 ; p<0.05)$ (Fig. 9C). Interestingly, this effect was also present under CNQX and NBQX (Fig. 9C) $(p<0.05)$. The prolongation of ensemble activity under PTX was less pronounced than under saclofen and CNQX (Fig. 9C). To better understand the network mechanisms, we analyzed data from dual MUA recordings (Fig. 9D).

Correlated ensembles were detected in $<35 \%$ cases from paired MUA recordings separated $285 \pm 30 \mu \mathrm{m}(n=9)$ (Fig. 9E). PTX significantly favored the spread of ensemble activity for 4-7 min after application (Fig. $9 F-H$ ). After $\sim 7 \mathrm{~min}$, local activity became unstable, and widespread epileptiform events were more frequent (Fig. 9I). The spread of local activity was also favored by saclofen (Fig. $9 H)(p<$ $0.05)$, but in contrast to PTX, this did not change neither focal nor widespread event frequency (Fig. 9I). CNQX (or NBQX) did not affect the local spread of activity, although it substantially increased ensemble duration (Fig. 9C,H). Because nonNMDA receptors mediate activation of FS interneurons (Menendez de la Prida, 2003), this probably reflected a disinhibitory effect as opposed to firing cessation. CNQX did reduce the frequency of both local ensembles and epileptiform events (Fig. 9I). Together, these results suggest that the spatial specificity of focal activity is strongly determined by local inhibition because impairment of $\mathrm{GABA}_{\mathrm{A}, \mathrm{B}}$ synaptic transmission favored merging of formerly non-overlapping ensembles.
Model and developmental dependence of focal activity

Finally, we tested whether focal activity was specific of the zero $\mathrm{Mg}^{2+}$ model or whether it could be induced by other manipulations such as increasing cell excitability using high $\mathrm{K}^{+}$media. Increasing $\left[\mathrm{K}^{+}\right]_{\mathrm{o}}$ to $5 \mathrm{~mm}$ induced focal ensemble activity in four of five minislices examined (data not shown). Focal events in 5 $\mathrm{mM} \mathrm{K}^{+}$were less frequent $(0.08 \pm 0.06 \mathrm{~Hz} ; n=4)$ than in the zero $\mathrm{Mg}^{2+}$ model $(p<0.05)$.

We also examined tissue from adult rats to discriminate pos(data not shown) population activity were also recorded in the adult isolated subiculum in zero $\mathrm{Mg}^{2+}(n=11)$. Although the frequency of these events, and the duration of focal activity, was lower than in juvenile tissue, their pharmacology was similar (Fig. 9C). This probably reflects the lower susceptibility of adult tissue sible developmental changes. Focal (Fig. 9B) and widespread

\begin{tabular}{lcccc}
\hline & IB & IB - & RS & FS \\
\hline Resting conductance, $G_{\text {rest }}(\mathrm{nS})$ & $9.4 \pm 2.1$ & $8.8 \pm 3.2$ & $5.5 \pm 3.9^{a}$ & $2.4 \pm 1.1^{b}$ \\
Maximum conductance changes, $G_{\text {synp }}(\mathrm{nS})$ & $19.5 \pm 11.1$ & $22.9 \pm 14.7$ & $10.9 \pm 6.7^{c}$ & $8.6 \pm 2.6^{c}$ \\
Maximum conductance peak, $\Delta$ Gpeak $(\%)$ & $141 \pm 85$ & $110 \pm 82$ & $118 \pm 62$ & $408 \pm 124^{d}$ \\
Conductance at Vrev depolarized peak (\%) & $71 \pm 29$ & $69 \pm 41$ & $68 \pm 11$ & $412 \pm 143^{e}$ \\
Number & 4 & 4 & 4 & 5 \\
\hline
\end{tabular}

${ }^{a}$ Resting conductance: RS versus $\mathrm{IB}+$ and $\mathrm{IB}-$, statistically different at $p<0.05$.

$\Delta$ Gpeak: FS versus other cell types, $p<0.005$

A

B

$\sigma=0.6$

$\sigma=1.0$

$\sigma=0.0$

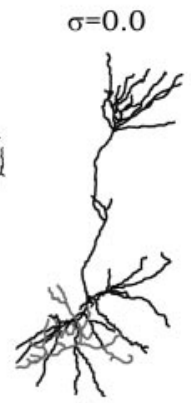

$200 \mu \mathrm{m}$
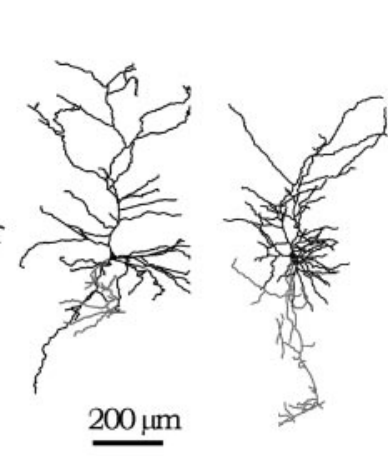

D

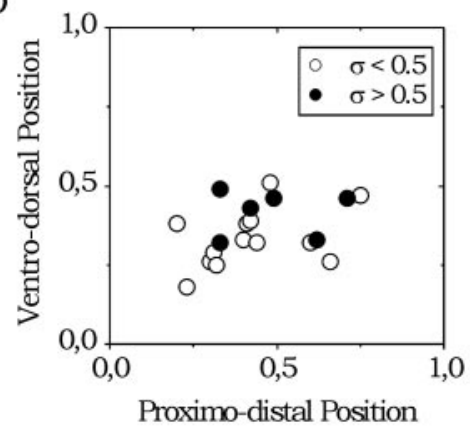

Table 2. Conductance changes associated with focal field activity

Figure 6. Morphological properties and the driving index. A, Scholl diagram of apical and basal dendritic arbors of cells exhibiting low $(\sigma=0.0 \pm 0.0 ; n=5)$ and high $(\sigma=0.7 \pm 0.2 ; n=4)$ driving index. Statistical difference was evident at distal dendritic crossings at $250-450 \mu \mathrm{m}$ from the soma and the driving index in all cells examined $(n=15)$. D, Spatial distribution of cells in each category. Positions are normalized.

to epilepsy. Interestingly, the synaptic component of single-cell firing during desynchronized states was lower in adult rats than in juvenile rats (Fig. $8 B$ ). This further suggests developmental differences in local connectivity between juvenile and adult tissue.

\section{Discussion}

The present study combines different recording and analytical methods to dissect the functional organization of rat subicular circuits using the zero $\mathrm{Mg}^{2+}$ model. The main results showed that focal and widespread field activity in the isolated subiculum is regulated by the firing correlation between leader and follower cells. Predictive factors for a cell to lead field activity include exhibiting the bursting phenotype, displaying a low firing threshold, and having more distal apical dendrites. A group of bursting cells constitutes the first glutamatergic type that initiates a local recruitment process that subsequently activates follower excita- 
A

B

desynch

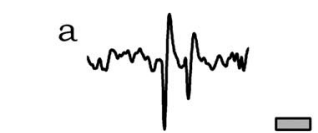

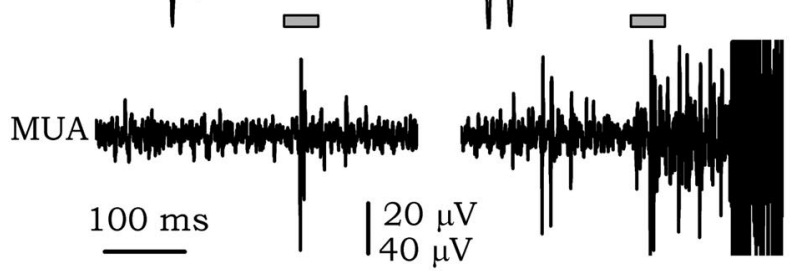

fp

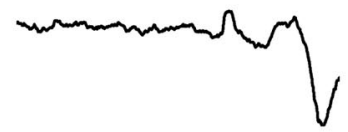

C

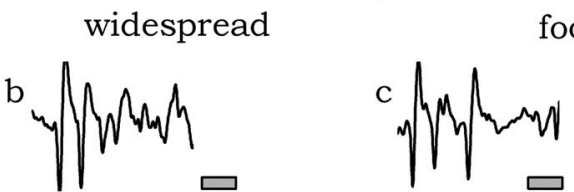

focal

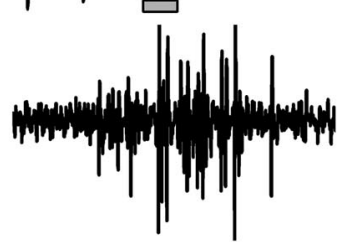

Figure 7. Simultaneous field and MUA recordings during desynchronized (desynch; $A$ ), widespread $(B)$, and focal $(C$ field activity. Insets a-c show additional details of firing activity.

A

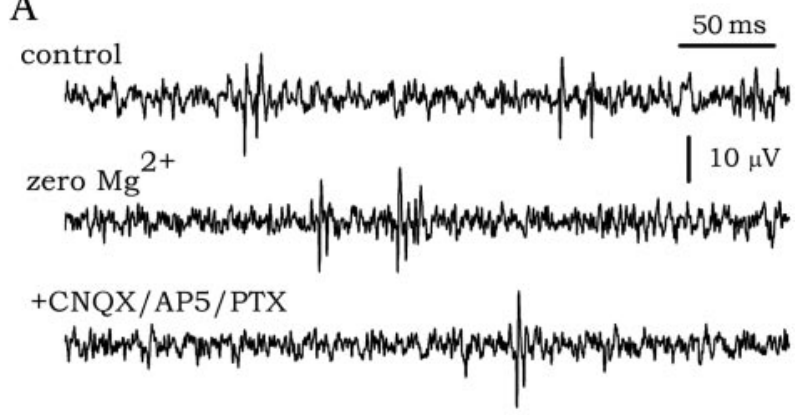

B

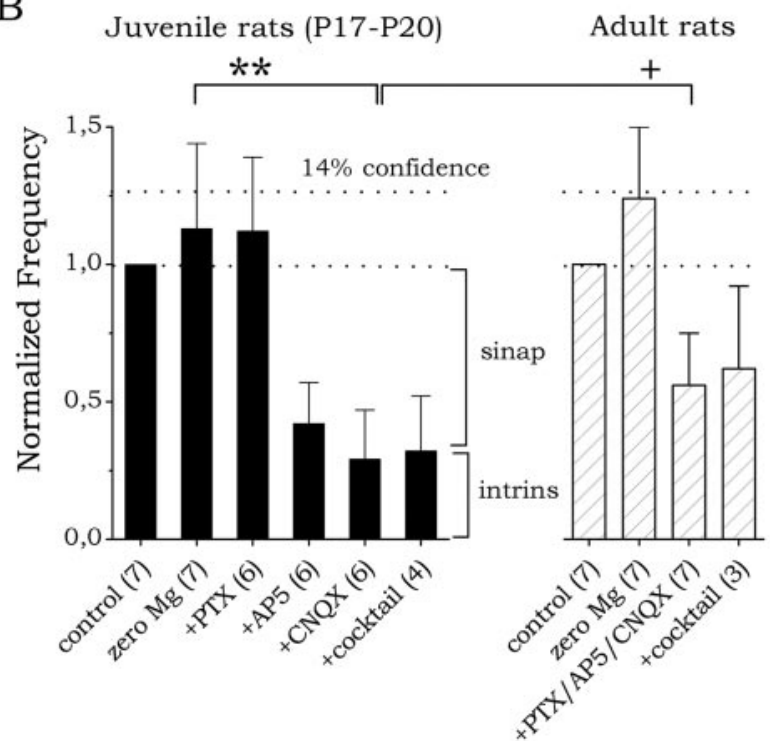

Figure 8. Pharmacological control of MUA firing during desynchronized activity. $A$, Representative MUA traces under control, zero $\mathrm{Mg}^{2+}$, and zero $\mathrm{Mg}^{2+}$ plus CNQX/AP5/PTX. B, Summary of results from pharmacological control of MUA firing in juvenile (left) and adult (right) rats. The number of slices is indicated. Statistical differences are shown: ${ }^{* *} p<$ $0.001 ;+p<0.05$.

tory and inhibitory cells. This is recorded extracellularly as a multi-unit local ensemble. The underlying synaptic events define a sequence of excitation and inhibition that controls the spatiotemporal firing. We found that with this functional design, inhi- bition mediates firing cessation by a feedback mechanism that is time-locked to the firing of leader cells. There is also a fast inhibitory control of firing propagation that regulates transition from focal to widespread activity.

\section{Functional organization of local} subicular circuits

To better understand the local operation of neuronal circuits, it is essential to dissect their cellular and synaptic components and to reveal their patterning of activity. One approach is to artificially enhance glutamatergic currents by using low $\mathrm{Mg}^{2+}$ media. There are several computational and technical reasons for this. First, by increasing time constant of excitation through NMDA receptors, the window for summation is enlarged, which facilitates the recruitment process (Herron et al., 1985; Jones and Heinemann, 1988). Second, it has been theoretically demonstrated that slow excitatory synapses favor sustained network activity (Wang, 1999). This would allow detection of formerly hidden functional circuits. Additionally, in the zero $\mathrm{Mg}^{2+}$ model (1) recurrent inhibition is not directly impaired (Ling and Benardo, 1995), and (2) NMDA receptors contribute a small tonic depolarizing current that inject firing into the network (LoTurco et al., 1990; Myme et al., 2003). We also tested the effect of increasing cell excitability under $5 \mathrm{mM} \mathrm{K}^{+}$and the possible developmental changes.

We found that focal activity is sculpted by the dynamic interactions between some bursting cells leading other bursting cells, RS cells, and FS interneurons. Because the activation of FS interneurons is time-locked to the firing of leader cells, inhibition is always adjusted by excitation. This is consistent with previous studies in the subiculum using extracellular stimulation (Finch et al., 1988; Taube, 1993; Behr et al., 1998; Menendez de la Prida, 2003). Follower bursting and RS cells generate a secondary front of excitation that could further increase cell firing and compensate with additional inhibition. As a result, local ensembles of active cells develop. Ensemble activity is very variable, suggesting that it does not always involve the same cellular groups. Using cell-attached recordings, we showed that a given cell variably participates in different focal events and that the definition of leader/follower has to be based on statistical average.

A classical theoretical constraint for the generation of focal activity is short-range excitation and long-range inhibition (Hartline et al., 1956; Gutkin et al., 2001). No morphological data are yet available to draw the picture in the subiculum, although broad excitatory arbors have been described (Berger et al., 1980; Finch et al., 1983; Harris et al., 2001). Computer simulations have shown that, even with excitation wider than inhibition, focal activity could still develop (Xing and Gerstein, 1996; Kang et al., 2003). Under this configuration, however, this activity could easily become unstable and spread throughout (Golomb and Amitai, 1997).

This picture is in agreement with our results: focal activity could generate widespread population activity. This transition is mainly controlled by fast GABAergic transmission. During the first minutes under PTX, cross-correlation significantly increased and widespread events emerged more frequently. Transition from focal to widespread activity is also regulated by glu- 
A

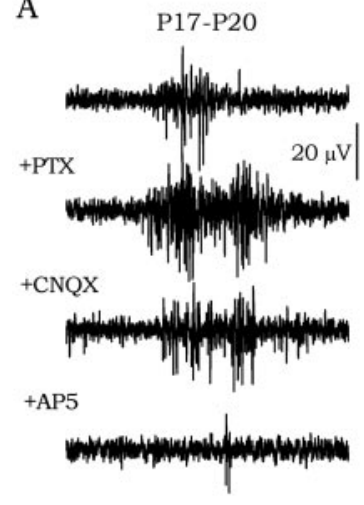

B
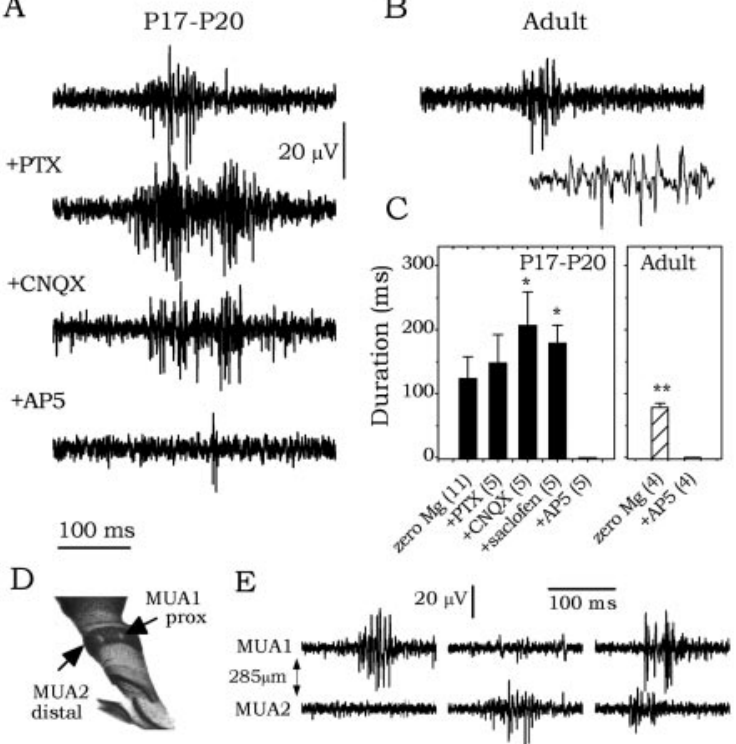

F

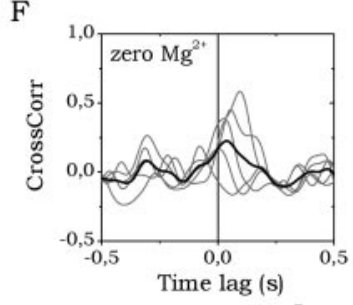

$\mathrm{E}$

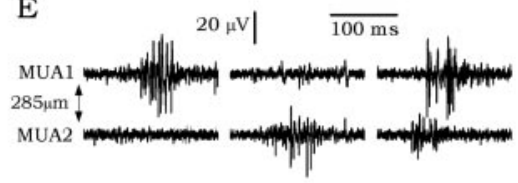

G

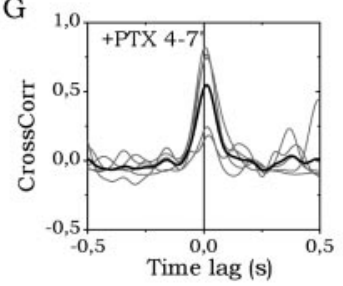

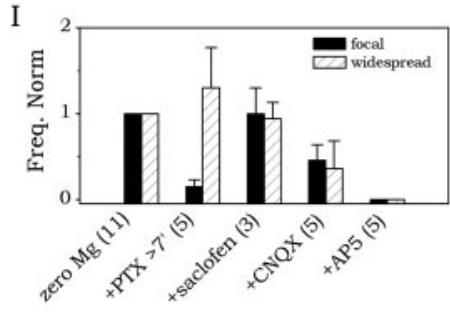

Figure 9. Pharmacological dissection of synaptic factors mediating focal activity. A, Fieldtriggered MUA ensembles during focal activity from juvenile tissue in zero $\mathrm{Mg}^{2+}$ media and after bath application of PTX, CNQX, and AP-5. B, Field-triggered MUA ensembles during focal activity from adult tissue in zero $\mathrm{Mg}^{2+}$ media. The inset shows additional details of firing activity. C, Summary of pharmacological results. The number of slices is indicated. D, Nissstained subicular minislice. A mark denoted the position of tungsten electrodes. $E$, Simultaneous MUA recordings during focal activity. $F$, Cross-correlation analysis of simultaneously recorded MUA firing rate. Results from five consecutive episodes are shown in gray; the mean is shown in black. G, Same as in Fafter 4-7 min of PTX application. Note the significant increase of cross-correlation. $H$, Summary of the cross-correlation analysis under different conditions: zero $\mathrm{Mg}^{2+}$, PTX (4-7 min), saclofen, and CNQX. The number of slices is indicated. I, Pharmacological dependence of the frequency of focal and widespread field events.

tamatergic components because CNQX decreased the frequency of focal and widespread activity in parallel. Possible factors underlying this transition include runaway excitation driven by follower glutamatergic cells. Because the circuit will compensate for that increase with more inhibition, additional mechanisms are needed to explain this transition. For example, it is possible that plasticity of synaptic activity at moderate and high-frequency firing could differentially affect glutamatergic and GABAergic synapses (Thomson and Deuchars, 1994; Galarreta and Hestrin, 1998), or significantly shift reversal potential for $\mathrm{GABA}_{\mathrm{A}}{ }^{-}$ mediated chloride currents (Thompson and Gähwiler, 1989; Staley and Proctor, 1999).

\section{Comparison with previous studies}

Focal field activity in the subiculum differs from other types of correlated activity described in the neocortex and the hippocampus. First, subicular focal activity is local and non-oscillatory as revealed by cross-correlation analysis. This is in contrast to many types of correlated activity that typically show oscillatory and propagating patterns (Steriade et al., 1993; Sanchez-Vives and McCormick, 2000; Wu et al., 2001) or to sharp-wave activity (Chrobak and Buzsaki, 1996). Instead, subicular focal activity is similar to spatially organized cortical ensembles (Mao et al., 2001; Cossart et al., 2003), although on a shorter time scale. Second, during focal activity, bursting cells lead population activity, whereas FS interneurons constitute a follower group. Such a temporal correlation is preserved during the buildup of widespread epileptiform activity. This is an important computational difference in comparison with models of slow propagating activity in which inhibitory firing precedes excitatory firing (Golomb and Ermentrout, 2002; Compte et al., 2003). Finally, repetitions of a precise firing pattern are not a feature of subicular focal activity (Cossart et al., 2003). Instead, the configuration of focal ensembles greatly varies with cells being recruited dynamically.

The firing correlation between driver and follower cells defines a succession of excitation and inhibition. This sequence is common in many preparations and represents the fact that local inhibition is secondarily recruited by excitatory circuits (Buzsaki, 1984). In contrast to other situations, in which excitation and inhibition were balanced continuously (Gutkin et al., 2001; Shu et al., 2003), subicular focal activity exhibited an initial dominance of excitation and a late prevalence of inhibition. Our analysis of synaptic conductances associated with focal activity revealed that conductance peaks were related with a slightly depolarized potential that subsequently hyperpolarized. This strongly suggests that the largest conductance increases (100$400 \%$ ) are dominated by GABA-mediated currents, which in concomitance with a net hyperpolarizing driving force would shunt excitatory inputs and suppress cell firing. This mechanism is similar to that reported in the visual (Borg-Graham et al., 1998; Hirsch et al., 1998; Anderson et al., 2000) and auditory cortices (Zhang et al., 2003; Wehr and Zador, 2003).

\section{The role of bursting and RS cells}

The leading role of bursting cells has been reported in different acute preparations (Miles and Wong, 1983; Changac-Amitai and Connors, 1989; Jensen and Yaari, 1997) and in chronic epileptic tissue (Sanabria et al., 2001; Cohen et al., 2002). Indeed, it has been shown that a permanent upregulation of intrinsic bursting contributes to hyperexcitability in chronic epilepsy (Wellmer et al., 2002). In contrast to single spikes, bursts may enhance the security of spike transmission, depending on the release probability and the facilitating nature of synapses (Miles and Wong, 1986; Thomson and Deuchars, 1994). Our results support a role of some bursting cells leading field activity, in agreement with previous reports in the subiculum (Harris and Stewart, 2001). However, we approached this problem using cell-attached recordings that do not alter the firing capability of cells. In addition, we examined the firing patterns in statistical terms and evaluated their impact in local firing control.

We found that bursting cells are not a leader population per se, although many bursting cells behaved like leaders $(\sigma>0.5)$. In contrast, RS cells mostly behaved as followers. However, focal and widespread activities constitute a probabilistic process, and a given cell could lead or follow the field during different episodes. Therefore, it is the cooperative interactions between different cell 
types that generate a population event. The positive correlation between the driving index and the firing threshold and the number of distal apical dendrites suggests that leader cells would be those that are more easily recruited. Also, cells having a statistical leader role were of the IB + and IB- bursting type, which confirms the critical contribution of these firing patterns in recurrent activity (Miles and Wong, 1983). Therefore, bursting subicular cells having more apical dendrites better contribute to collect and distribute activity through the network. The distal dendrites of these neurons can be also the site of the initiation of regenerative calcium spikes, which favor cell recruitment (Yuste et al., 1994; Kamondi et al., 1998; Larkum et al., 1999).

The role of followers in this scheme should not be considered secondary. This is particularly the case of RS cells, which displayed a low firing rate and high firing threshold. This determines that RS cells were sharply recruited and, therefore, the contrast between response and no-response is enhanced at the onset of field activity. However, RS cells remained silent during some episodes of focal activity, which possibly leaves them available for being recruited by other ensembles. In contrast, because follower cells inject firing into the circuit at the onset of field activity, they can participate in runaway excitation.

\section{References}

Anderson JS, Carandini M, Ferster D (2000) Orientation tuning of input conductance, excitation, and inhibition in cat primary visual cortex. J Neurophysiol 84:909-926.

Behr J, Heinemann U (1996) Low Mg2+ induced epileptiform activity in the subiculum before and after disconnection from rat hippocamapl and entorhinal cortex slices. Neurosci Lett 205:25-28.

Behr J, Gloveli T, Heinemann U (1998) The perforant path projection from the medial entorhinal cortex layer III to the subiculum in the rat combined hippocampal-entorhinal cortex slice. Eur J Neurosci 10:1011-1018.

Berger TW, Swanson GW, Milner TA, Lynch GS, Thompson RF (1980) Reciprocal anatomical connections between hippocampus and subiculum in the rabbit evidence for subicular innervation of regio superior. Brain Res 183:265-276.

Borg-Graham LJ (2001) The computation of directional selectivity in the retina occurs presynaptic to the ganglion cell. Nat Neurosci 4:176-183.

Borg-Graham LJ, Monier C, Fregnac Y (1998) Visual input evokes transient and strong shunting inhibition in visual cortical neurons. Nature 393:369-373.

Buzsaki G (1984) Feed-forward inhibition in the hippocampal formation. Prog Neurobiol 22:131-153.

Chagnac-Amitai Y, Connors BW (1989) Synchronized excitation and inhibition driven by intrinsically bursting neurons in neocortex. J Neurophysiol 62:1149-1162.

Chamberlin NL, Traub RD, Dingledine R (1990) Role of EPSPs in initiation of spontaneous synchronized burst firing in rat hippocampal neurons bathed in high potassium. J Neurophysiol 64:1000-1008.

Chrobak JJ, Buzsaki G (1996) High-frequency oscillations in the output networks of the hippocampal-entorhinal axis of the freely behaving rat. J Neurosci 16:3056-3066.

Cohen I, Miles R (2000) Contributions of intrinsic and synaptic activities to the generation of neuronal discharges in in vitro hippocampus. J Physiol (Lond) 524:485-502.

Cohen I, Navarro V, Clemenceau S, Baulac M, Miles R (2002) On the origin of interictal activity in human temporal lobe epilepsy in vitro. Science 298:1418-1421.

Colino A, De Molina FF (1986) Inhibitory response in entorhinal and subicular cortices after electrical stimulation of the lateral and basolateral amygdala of the rat. Brain Res 378:416-419.

Compte A, Sanchez-Vives MV, McCormick DA, Wang XJ (2003) Cellular and network mechanisms of slow oscillatory activity $(<1 \mathrm{~Hz})$ and wave propagations in a cortical network model. J Neurophysiol 89:2707-2725.

Cossart R, Aronov D, Yuste R (2003) Attractor dynamics of network UP states in the neocortex. Nature 423:283-288.

Ekstrom AD, Kahana MJ, Caplan JB, Fields TA, Isham EA, Newman EL, Fried
I (2003) Cellular networks underlying human spatial navigation. Nature 425:184-188.

Finch DM, Nowlin NL, Babb TL (1983) Demonstration of axonal projections of neurons in the rat hippocampus and subiculum by intracellular injection of HRP. Brain Res 271:201-216.

Finch DM, Tan AM, Isokawa-Akesson M (1988) Feedforward inhibition of the rat entorhinal cortex and subicular complex. J Neurosci 8:2213-2226.

Galarreta M, Hestrin S (1998) Frequency-dependent synaptic depression and the balance of excitation and inhibition in the neocortex. Nat Neurosci 1:587-594.

Goldman-Rakic PS (1995) Cellular basis of working memory. Neuron 14:477-485.

Golomb D, Amitai Y (1997) Propagating neuronal discharges in neocortical slices: computational and experimental study. J Neurophysiol 78:1199-1211.

Golomb D, Ermentrout GB (2002) Slow excitation supports propagation of slow pulses in networks of excitatory and inhibitory populations. Physiol $\operatorname{Rev}[\mathrm{E}]$ 65:061911.

Greene JRT, Totterdell S (1997) Morphology and distribution of electrophysiologically defined classes of pyramidal and nonpyramidal neurons in rat ventral subiculum in vitro. J Comp Neurol 380:395-408.

Gutkin BS, Laing CR, Colby CL, Chow CC, Ermentrout GB (2001) Turning on and off with excitation: the role of spike-timing asynchrony and synchrony in sustained neural activity. J Comput Neurosci 11:121-134.

Harris E, Stewart M (2001) Intrinsic connectivity of the rat subiculum: II. Properties of synchronous spontaneous activity and a demonstration of multiple generator regions. J Comp Neurol 436:506-518.

Harris E, Witter MP, Weinstein G, Stewart M (2001) Intrinsic connectivity of the rat subiculum: I. Dentritic morphology and patterns of axonal arborization by pyramidal neurons. J Comp Neurol 436:490-505.

Hartline HK, Wagner HG, Ratliff F (1956) Inhibition in the eye of Limulus. J Gen Physiol 39:651-673.

Herron CE, Lester RA, Coan EJ, Collingridge GL (1985) Intracellular demonstration of an N-methyl-D-aspartate receptor mediated component of synaptic transmission in the rat hippocampus. Neurosci Lett 60:19-23.

Hirsch JA, Alonso JM, Reid RC, Martinez LM (1998) Synaptic integration in striate cortical simple cells. J Neurosci 18:9517-9528.

Jensen MS, Yaari Y (1997) Role of intrinsic burst firing, potassium accumulation, and electrical coupling in the elevated potassium model of hippocampal epilepsy. J Neurophysiol 77:1224-1233.

Jones RS, Heinemann U (1988) Synaptic and intrinsic responses of medical entorhinal cortical cells in normal and magnesium-free medium in vitro. J Neurophysiol 59:1476-1496.

Kamondi A, Acsady L, Buzsaki G (1998) Dendritic spikes are enhanced by cooperative network activity in the intact hippocampus. J Neurosci 18:3919-3928.

Kang K, Shelley M, Sompolinsky H (2003) Mexican hats and pinwheels in visual cortex. Proc Natl Acad Sci USA 100:2848-2853.

Kawaguchi Y (2001) Distinct firing patterns of neuronal subtypes in coritcal synchronized activity. J. Neurosci 21:7261-7272.

Koch C, Douglas R, Wehmeier U (1990) Visibility of synaptically induced conductance changes: theory and simulations of anatomically characterized cortical pyramidal cells. J Neurosci 10:1728-1744.

Larkum ME, Zhu JJ, Sakmann B (1999) A new cellular mechanism for coupling inputs arriving at different cortical layers. Nature 398:338-341.

Ling DS, Benardo LS (1995) Recruitment of GABAA inhibition in rat neocortex is limited and not NMDA dependent. J Neurophysiol 74:2329-2335.

LoTurco JJ, Mody I, Kriegstein AR (1990) Differential activation of glutamate receptors by spontaneously released transmitter in slices of neocortex. Neurosci Lett 114:265-271.

Mao BQ, Hamzei-Sichani F, Aronov D, Froemke RC, Yuste R (2001) Dynamics of spontaneous activity in neocortical slices. Neuron 32:883-898.

Menendez de la Prida L (2003) Control of bursting by local inhibition in the rat subiculum in vitro. J Physiol (Lond) 549 1:219-230.

Menendez de la Prida L, Sanchez-Andres JV (1999) Nonlinear frequencydependent synchronization in the developing hippocampus. J Neurophysiol 82:202-208.

Menendez de la Prida L, Suarez F, Pozo MA (2002) The effect of different morphological sampling criteria on the fraction of bursting cells recorded in the rat subiculum in vitro. Neurosci Lett 322:49-52.

Menendez de la Prida L, Suarez F, Pozo MA (2003) Electrophysiological and 
morphological diversity of neurons from the rat subicular complex in vitro. Hippocampus, 13:718-744.

Miles R, Wong RK (1983) Single neurones can initiate synchronized population discharge in the hippocampus. Nature 306:371-373.

Miles R, Wong RKS (1986) Excitatory synaptic interactions between CA3 neurones in the guinea-pig hippocampus. J Physiol (Lond) 373:397-418.

Miles R, Wong RKS, Traub RD (1984) Synchronized afterdischarges in the hippocampus: contribution of local synaptic interactions. Neuroscience 12:1179-1189.

Myme CI, Sugino K, Turrigiano GG, Nelson SB (2003) The NMDA-toAMPA ratio at synapses onto layer $2 / 3$ pyramidal neurons is conserved across prefrontal and visual cortices. J Neurophysiol 90:771-779.

Neher E (1994) Correction for liquid junction potentials in patch-clamp experiments. In: Single channel recording, Ed 2 (Sakmann B, Neher E, eds), pp 147-153. New York: Plenum.

Sanabria ER, Su H, Yaari Y (2001) Initiation of network bursts by Ca2+dependent intrinsic bursting in the rat pilocarpine model of temporal lobe epilepsy. J Physiol (Lond) 532:205-216.

Sanchez-Vives MV, McCormick DA (2000) Cellular and network mechanisms of rhythmic recurrent activity in neocortex. Nat Neurosci 3:1027-1034.

Scholl D (1953) Dendritic organization in the neurons of the visual and motor cortices of the rat. J Anat 87:387-406.

Sharp PE (1999) Complimentary roles for hippocampal versus subicular/ entorhinal place cells in coding place, context, and events. Hippocampus 9:432-443.

Sharp PE, Green C (1994) Spatial correlates of firing patterns of single cells in the subiculum of freely moving rat. J Neurosci 14:2339-2356.

Shu Y, Hasenstaub A, McCormick DA (2003) Turning on and off recurrent balanced cortical activity. Nature 423:288-293.

Spruston N, Jaffe DB, Williams SH, Johnston D (1993) Voltage- and spaceclamp errors associated with the measurement of electrotonically remote synaptic events. J Neurophysiol 70:781-802.

Staff NP, Jung HY, Thiagarajan T, Yao M, Spruston N (2000) Resting and active properties of pyramidal neurons in subiculum and CA1 of rat hippocampus. J Neurophysiol 84:2398-2408.

Staley KJ, Proctor WR (1999) Modulation of mammalian dendritic $\mathrm{GABA}(\mathrm{A})$ receptor function by the kinetics of $\mathrm{Cl}$ - and $\mathrm{HCO}$ - transport. J Physiol (Lond) 519:693-712.

Stanford IM, Traub RD, Jefferys JGR (1998) Limbic gamma rhythms. II. Synaptic and intrinsic mechanisms underlying spike doublets in oscillating subicular neurons. J Neurophysiol 80:162-171.

Steriade M, Nunez A, Amzica F (1993) A novel slow ( $<1 \mathrm{~Hz}$ ) oscillation of neocortical neurons in vivo: depolarizing and hyperpolarizing components. J Neurosci 13:3252-3265.
Stewart M, Wong RK (1993) Intrinsic properties and evoked responses of guinea-pig subicular neurons in vitro. J Neurophysiol 70:232-245.

Taube JS (1993) Electrophysiological properties of neurons in the rat subiculum in vivo. Exp Brain Res 96:304-318.

Taube JS (1995) Place cells recorded in the parasubiculum of freely moving rats. Hippocampus 5:569-583.

Taube JS, Basset JP (2003) Persistent neural activity in head direction cells. Cereb Cortex 13:1162-1172.

Thompson SM, Gähwiler BH (1989) Activity-dependent disinhibition. I. Repetitive stimulation reduces IPSP driving force and conductance in the hippocampus in vitro. J Neurophysiol 61:501-511.

Thomson AM, Deuchars J (1994) Temporal and spatial properties of local circuits in neocortex. Trends Neurosci 17:119-126.

Traub RD, Dingledine R (1990) Model of synchronized epileptiform bursts induced by high potassium in CA3 region of rat hippocampal slice. Role of spontaneous EPSPs in initiation. J Neurophysiol 64:1009-1018.

Traub RD, Jefferys JG, Whittington MA (1994) Enhanced NMDA conductance can account for epileptiform activity induced by low $\mathrm{Mg} 2+$ in the rat hippocampal slice. J Physiol (Lond) 478:379-393.

Walther H, Lambert JD, Jones RS, Heinemann U, Hamon B (1986) Epileptiform activity in combined slices of the hippocampus, subiculum and entorhinal cortex during perfusion with low magnesium medium. Neurosci Lett 69:156-161.

Wang X-J (1999) Synaptic basis of cortical persistent activity: the importance of NMDA receptors to working memory. J Neurosci 19:9587-9603.

Wehr M, Zador AM (2003) Balanced inhibition underlies tuning and sharpens spike timing in auditory cortex. Nature 426:442-446.

Wellmer J, Su H, Beck H, Yaari Y (2002) Long-lasting modification of intrinsic discharge properties in subicular neurons following status epilepticus. Eur J Neurosci 16:259-266.

Wenner P, O'Donovan MJ (2001) Mechanisms that initiate spontaneous network activity in the developing chick spinal cord. J Neurophysiol 86:1481-1498.

Wu JY, Guan L, Bai L, Yang Q (2001) Spatiotemporal properties of an evoked population activity in rat sensory cortical slices. J Neurophysiol 86:2461-2474.

Xing J, Gerstein GL (1996) Networks with lateral connectivity. II. Development of neuronal grouping and corresponding receptive field changes. J Neurophysiol 75:200-216.

Yuste R, Gutnick MJ, Saar D, Delaney KR, Tank DW (1994) Ca2 + accumulations in dendrites of neocortical pyramidal neurons: an apical band and evidence for two functional compartments. Neuron 13:23-43.

Zhang LI, Tan AY, Schreiner CE, Merzenich MM (2003) Topography and synaptic shaping of direction selectivity in primary auditory cortex. Nature 424:201-205. 